\title{
Effect of a do-not-resuscitate order on the quality of care in acute heart failure patients: a single- center cohort study
}

This article was published in the following Dove Press journal: International Journal of General Medicine

\author{
Shunsuke Kojima' \\ Eiji Hiraoka' \\ Junya Arai' \\ Yosuke Homma ${ }^{2}$ \\ Yasuhiro Norisue ${ }^{3}$ \\ Osamu Takahashi ${ }^{4}$ \\ Taihei Soma' \\ Toshihiko Suzuki ${ }^{5}$ \\ Masahiko Noguchi ${ }^{6}$ \\ Kentaro Shibayama ${ }^{6}$ \\ Kotaro Obunai ${ }^{6}$ \\ Hiroyuki Watanabe ${ }^{6}$ \\ 'Department of Internal Medicine, \\ 2Department of Emergency Medicine, \\ ${ }^{3}$ Department of Critical Care and \\ Pulmonary Medicine, Tokyo Bay \\ Urayasu Ichikawa Medical Center, \\ Todaijima, Urayasu-city, Chiba 279 - \\ 000 I, Japan; ${ }^{4}$ Department of Internal \\ Medicine, St Luke's International \\ Hospital, Chuo-ku, Tokyo 104-8560, \\ Japan; ${ }^{5}$ Department of Nephrology, \\ Endocrinology, and Diabetes, \\ ${ }^{6}$ Department of Cardiology, Tokyo \\ Bay Urayasu Ichikawa Medical Center, \\ Todaijima, Urayasu-city, Chiba \\ 279-000I, Japan
}

Correspondence: Eiji Hiraoka Department of Internal Medicine, Tokyo Bay Urayasu Ichikawa Medical Center, 3-4-32, Todaijima, Urayasu-city, Chiba 279-000I, Japan

Tel $+8 \mid 4735$ I 310।

$\mathrm{Fax}+814735$ I 6237

Email eijih@jadecom.jp
Background: A do-not-resuscitate (DNR) order is reportedly associated with a decrease in performance measures, but it should not be applied to noncardiopulmonary resuscitation procedures. Good performance measures are associated with improvement in heart failure outcomes. Aim: To analyze the influence of DNR order on performance measures of heart failure at our hospital, where lectures on DNR order are held every 3 months.

Design: Retrospective cohort study.

Methods: The medical report of patients with acute heart failure who were admitted between April 2013 and March 2015 were retrospectively analyzed. We collected demographic data, information on the presence or absence of DNR order within 24 hours of admission, and inhospital mortality. Performance measures of heart failure, including assessment of cardiac function and discharge prescription of angiotensin-converting enzyme inhibitor or angiotensin receptor blocker and beta-blocker for left ventricular systolic dysfunction and anticoagulant for atrial fibrillation, were collected and compared between groups with and without DNR orders. Results: In 394 total patients and 183 patients with left ventricular systolic dysfunction, 114 (30\%) and 44 (24\%) patients, respectively, had a DNR order. Patients with a DNR order had higher inhospital mortality. There were no significant differences between the two groups in terms of the four quality measures (left ventricular function assessment, angiotensin-converting enzyme inhibitor or angiotensin receptor blocker, beta-blocker, and anticoagulant).

Conclusion: DNR orders did not affect performance measures, but they were associated with higher inhospital mortality among acute heart failure patients.

Keywords: do-not-resuscitate discussion, DNR order, acute heart failure, quality-of-care performance

\section{Introduction}

Heart failure (HF) is a major and inevitable public health issue worldwide. Between 2004 and 2014, although death rates due to cardiovascular disease (CVD) declined by $25.3 \%$, and the actual number of CVD deaths decreased by $6.7 \%$, CVD remains one of the most common leading causes of death. ${ }^{1}$ In Japan, the prevalence of HF is increasing, especially in elderly populations, and one report estimated that the number of Japanese outpatients with left ventricular dysfunction would increase gradually as patients age, reaching 1.3 million by $2030 .^{2}$ Performance measures in hospitalized HF patients have been developed to improve their care. ${ }^{3}$ Adhering to these measures on routine daily care was found to contribute to a decrease in mortality in acute heart failure (AHF) patients. ${ }^{4}$ 
Documentation of a do-not-resuscitate (DNR) order is a part of end-of-life care intended to allow patients to forgo cardiopulmonary resuscitation (CPR) in the event of cardiac arrest. ${ }^{5,6}$ They are only applied to cases of cardiac arrest, and they cannot be applied to any situation other than cardiac arrest. ${ }^{5,6}$ In the USA, a DNR order was associated with a decrease in performance measures and higher mortality in AHF patients. ${ }^{7} \mathrm{HF}$ is a progressive disease, and its prognosis is not good. The American Heart Association (AHA) recommended that physicians should start end-of-life care discussion for future event, including resuscitation preference during the earlier stage of the illness. ${ }^{8}$ However, a DNR order poses a risk of worse prognosis due to worsening quality of HF care. ${ }^{?}$

A DNR order was reported to affect decision making in non-CPR procedures not only in the USA but also in Japan. ${ }^{9,10}$ Therefore, it is important to educate physicians with the definition of a DNR order and its proper implementation to prevent its misuse. In our hospital, we started lectures on DNR order for physicians in 2013. This retrospective study evaluated the influence of DNR status on the quality of inhospital clinical performance in acute AHF patients.

\section{Methods}

\section{Subjects}

This retrospective, single-center, cohort study included patients who were admitted to our acute care teaching hospital with a primary diagnosis of AHF between April 2013 and March 2015. The medical charts of adult patients ( $>18$ years) with primary diagnosis of AHF on admission were reviewed. We confirmed the diagnosis of HF based on the Framingham criteria. ${ }^{11}$

\section{Setting}

Our hospital is an acute teaching hospital, where AHF patients are under the care of a general internal medicine (GIM) team, which consists of two or three residents and one hospitalist attending physician. Cardiologists are always available as consultant. GIM residents rotate every 3 months and spend 6 months in internal medicine wards in our hospital per year, which meets the requirement of GIM residency training in Japan. Since 2013, we give a lecture on the definition of DNR order and its proper implementation at the beginning of each 3 months' rotation of medical wards (Figure 1). Therefore, residents and hospitalist attending physicians have a chance to participate in the lecture two and four times a year, respectively.

\section{Data collection}

Patients' demographic data, DNR status within 24 hours after admission, and laboratory data on admission as well as echocardiography data during the hospitalization and inhospital mortality were collected. According to AHA guidelines, performance measures of inpatient HF include five items: 1) evaluation of left ventricular systolic function, 2) angiotensinconverting enzyme inhibitor (ACEi) or angiotensin receptor blocker (ARB) for left ventricular systolic dysfunction (LVSD), 3) anticoagulant at discharge for HF patients with atrial fibrillation (AF), 4) discharge instructions, and 5) adult smoking cessation advice/counseling. ${ }^{3}$ We chose the cardiac function assessment, ACEi, or ARB use for LVSD and anticoagulant for AF because discharge instruction and smoking cessation advice are often performed but not documented in hospital charts; therefore, those data may be imprecise. Because betablocker is also an important treatment for LVSD to improve mortality and quality of life, it was also added as a quality measure. LVSD is defined as ejection fraction of $40 \%$ or lower. ${ }^{3}$ Patients who were not prescribed ACEi, ARB, beta-blocker, or anticoagulant for documented reasons were excluded: ACEi or ARB for hypotension, renal insufficiency, or hyperkalemia; beta-blocker for hypotension, bradycardia, asthma, or inotrope use; anticoagulant for bleeding event or poor prognosis. We also excluded patients who died during hospitalization.

\section{Informed consent and institutional review board approval}

This study protocol was approved by the institutional review board of Tokyo Bay Urayasu Ichikawa Medical Center. Because of the anonymous nature of the data, the requirement for informed consent was waived.

\section{Statistical analysis}

Continuous variables were expressed as mean $\pm \mathrm{SD}$, and discrete variables were summarized as percentages. Continuous variables and dichotomous variables were analyzed and compared using $t$-test and chi-squared test, respectively. All statistical analyses were conducted using SPSS version 22.0 (IBM Corporation, Armonk, NY, USA).

\section{Results \\ Patient characteristics}

The total number of patients was 394, of whom 183 had LVSD. The mean age was $73 \pm 14$ years, and $56 \%$ were men. The characteristics, comorbidities, and outcomes based on the presence of DNR orders for all patients and for patients 
with LVSD are presented in Tables 1 and 2, respectively. Approximately $30 \%$ of all patients and $24 \%$ of LVSD patients had DNR orders on admission (Tables 1 and 2). Patients with DNR orders tended to be older and were more likely to be women. They were more likely to have incomplete decision-making capacity, to be ADL-dependent, and to have dementia than patients without DNR orders (Tables 1 and 2). Meanwhile, there were no significant differences between the presence and the absence of DNR orders in terms of other comorbidities, including kidney dysfunction and lung disease. Inhospital mortality was $6.1 \%$ and it was significantly higher in the DNR group than the non-DNR group.

\section{Quality measures}

Assessment of cardiac function by echocardiography In terms of rate of assessment of cardiac function by echocardiography, almost all patients (99\%) underwent echocardiography, and there was no statistically significant difference between the DNR and the non-DNR groups (Table 3).

\section{Prescription rate of ACEi or ARB and beta-blocker on discharge for treatment of HF with reduced ejection fraction}

Of 394 patients, 183 (46\%) had LVSD, of whom 13 (7\%) died during hospitalization. In 13 patients $(7.6 \%)$ of the 170 survivors, beta-blocker was considered but was not prescribed because of contraindications, such as hypotension, bradycardia, asthma, or inotrope use. In the remaining 122 DNR and 35 non-DNR patients, 148 (94\%) were prescribed a beta-blocker on discharge. There was no statistically significant difference between the DNR and non-DNR groups (Table 3).

Table I Patient characteristics according to DNR status

\begin{tabular}{|c|c|c|c|}
\hline Characteristics & Absence of DNR order $(\mathrm{N}=\mathbf{2 8 0})$ & Presence of DNR order $(N=1 \mid 4)$ & $P$-value \\
\hline Age, years & $69 \pm 14$ & $82 \pm 8$ & $<0.001$ \\
\hline Age $>75$ years & $124(44)$ & $88(77)$ & $<0.001$ \\
\hline Sex, male & $173(62)$ & $46(40)$ & $<0.001$ \\
\hline \multicolumn{4}{|l|}{ Comorbidities } \\
\hline Hypertension & $163(58)$ & $77(67)$ & 0.09 \\
\hline COPD & $13(4.6)$ & $3(2.6)$ & 0.57 \\
\hline Malignancy & $19(6.8)$ & $10(8.8)$ & 0.53 \\
\hline CKD & $48(17)$ & $24(2 I)$ & 0.39 \\
\hline Hemodialysis & $23(8.2)$ & $6(5.3)$ & 0.40 \\
\hline DM & $85(30)$ & $31(27)$ & 0.63 \\
\hline \multicolumn{4}{|l|}{ Medical history } \\
\hline Stroke & $35(13)$ & $17(15)$ & 0.52 \\
\hline Myocardial infarction & $32(11)$ & II (9.6) & 0.72 \\
\hline $\mathrm{PCl}$ & $18(6.4)$ & $6(5.3)$ & 0.82 \\
\hline CABG & $10(3.6)$ & $6(5.3)$ & 0.41 \\
\hline Valve surgery & $7(2.5)$ & $2(1.8)$ & 1.0 \\
\hline Pace maker & $6(2.1)$ & $5(4.4)$ & 0.31 \\
\hline Current smoking & $63(23)$ & II (9.7) & $<0.001$ \\
\hline History of AHF hospitalization & $92(35)$ & $44(40)$ & 0.29 \\
\hline Dementia & $28(\mathrm{II})$ & $47(4 I)$ & $<0.001$ \\
\hline ADL-dependent & $4 \mid(15)$ & $52(46)$ & $<0.001$ \\
\hline Decision-making capacity: complete & $263(94)$ & $74(66)$ & $<0.001$ \\
\hline Systolic blood pressure, $\mathrm{mmHg}$ & $152 \pm 35$ & $149 \pm 39$ & 0.59 \\
\hline Diastolic blood pressure, $\mathrm{mmHg}$ & $91 \pm 23$ & $83 \pm 24$ & 0.004 \\
\hline Heart rate, beats/minute & $99 \pm 28$ & $90 \pm 24$ & 0.005 \\
\hline Acute coronary syndrome & $42(15)$ & $10(8.8)$ & 0.10 \\
\hline Acute infection & $38(15)$ & $14(14)$ & 1.0 \\
\hline Echocardiography: ejection fraction, \% & $41 \pm 16$ & $44 \pm 16$ & 0.09 \\
\hline \multicolumn{4}{|l|}{ Laboratory data } \\
\hline Hemoglobin, g/dL & $12.5 \pm 2.4$ & $11.0 \pm 2.1$ & $<0.001$ \\
\hline Blood urea nitrogen, $\mathrm{mg} / \mathrm{dL}$ & $25 \pm 16$ & $31 \pm 18$ & 0.003 \\
\hline Creatinine, $\mathrm{mg} / \mathrm{dL}$ & $1.8 \pm 2.6$ & $1.7 \pm 1.7$ & 0.58 \\
\hline Inhospital mortality & $7(2.5)$ & $17(15)$ & $<0.001$ \\
\hline
\end{tabular}

Note: Values are presented as mean \pm SD or $\mathrm{n}(\%)$.

Abbreviations: DNR, do-not-resuscitate order; COPD, chronic obstructive pulmonary disease; CKD, chronic kidney disease; DM, diabetes mellitus; PCl, percutaneous coronary intervention; CABG, coronary artery bypass graft; AHF, acute heart failure; ADL, activities of daily living. 
Table 2 Characteristics of HF patients with reduced ejection fraction according to DNR status

\begin{tabular}{|c|c|c|c|}
\hline Characteristics & Absence of DNR $(\mathrm{N}=139)$ & Presence of DNR $(\mathrm{N}=44)$ & $P$-value \\
\hline Age, years & $65 \pm 5$ & $81 \pm 9$ & $<0.001$ \\
\hline Age $>75$ years & $48(35)$ & $30(68)$ & $<0.001$ \\
\hline Male & $105(77)$ & $28(64)$ & 0.12 \\
\hline \multicolumn{4}{|l|}{ Comorbidities } \\
\hline Hypertension & $69(50)$ & $26(60)$ & 0.30 \\
\hline COPD & $2(1.4)$ & $\mathrm{I}(2.3)$ & 0.56 \\
\hline Malignancy & $8(5.8)$ & $5(11)$ & 0.31 \\
\hline CKD & $19(14)$ & $10(23)$ & 0.16 \\
\hline HD & II (7.9) & $3(6.8)$ & 1.0 \\
\hline DM & $4 \mid(30)$ & $15(34)$ & 0.58 \\
\hline \multicolumn{4}{|l|}{ Medical history } \\
\hline Stroke & $16(12)$ & II (25) & 0.048 \\
\hline Myocardial infarction & $18(13)$ & $8(18)$ & 0.46 \\
\hline $\mathrm{PCl}$ & $8(5.8)$ & $2(4.5)$ & 1.0 \\
\hline CABG & $4(2.9)$ & $4(9.1)$ & 0.096 \\
\hline Valve surgery & $\mathrm{I}(0.7)$ & 0 & 1.0 \\
\hline Pacemaker & $\mathrm{I}(0.7)$ & $\mathrm{I}(2.3)$ & 0.42 \\
\hline Current smoker & $43(3 \mathrm{I})$ & $8(18)$ & 0.26 \\
\hline AHF hospitalization & $44(34)$ & $21(48)$ & 0.11 \\
\hline Dementia & $13(9.4)$ & $20(46)$ & $<0.001$ \\
\hline ADL-dependent & $12(8.6)$ & $19(43)$ & $<0.001$ \\
\hline Decision-making capacity: complete & $132(95)$ & $27(62)$ & $<0.001$ \\
\hline Systolic blood pressure, $\mathrm{mmHg}$ & $148 \pm 34$ & $144 \pm 37$ & 0.62 \\
\hline Diastolic blood pressure, $\mathrm{mmHg}$ & $95 \pm 23$ & $87 \pm 29$ & 0.08 \\
\hline Heart rate, beats/minute & $108 \pm 29$ & $94 \pm 26$ & 0.004 \\
\hline Acute coronary syndrome & $26(19)$ & $8(18)$ & 1.0 \\
\hline Acute infection & $20(15)$ & $6(15)$ & 1.0 \\
\hline Echocardiography: ejection fraction, \% & $27 \pm 8$ & $27 \pm 8$ & 0.69 \\
\hline \multicolumn{4}{|l|}{ Laboratory data } \\
\hline Hemoglobin, g/dL & $13.2 \pm 2.7$ & $11.2 \pm 2.1$ & $<0.001$ \\
\hline Blood urea nitrogen, $\mathrm{mg} / \mathrm{dL}$ & $26 \pm 16$ & $39 \pm 24$ & 0.002 \\
\hline Creatinine, $\mathrm{mg} / \mathrm{dL}$ & $1.8 \pm 2.9$ & $1.8 \pm 1.6$ & 0.84 \\
\hline Inhospital mortality & $6(4.3)$ & $7(16)$ & 0.016 \\
\hline
\end{tabular}

Note: Values are presented as mean \pm SD or $n(\%)$.

Abbreviations: HF, heart failure; DNR, do-not-resuscitate order; COPD, chronic obstructive pulmonary disease; CKD, chronic kidney disease; HD, heart disease; DM, diabetes mellitus; $\mathrm{PCl}$, percutaneous coronary intervention; CABG, coronary artery bypass graft; AHF, acute heart failure; ADL, activities of daily living.

Table 3 DNR order and quality measures among acute heart failure inpatients

\begin{tabular}{lllll}
\hline Quality measure & Absence of DNR order & Presence of DNR order & P-value & RR (95\% CI) \\
\hline Echocardiography & $280 / 280(100 \%)$ & $113 / 114(99 \%)$ & 0.29 & $0.99(0.97-1.01)$ \\
Anticoagulation for atrial fibrillation & $71 / 73(97 \%)$ & $18 / 18(100 \%)$ & 1.0 & $1.03(0.99-1.07)$ \\
Beta-blocker for LVSD & $115 / 122(94 \%)$ & $33 / 35(94 \%)$ & 1.0 & $1.0(0.91-1.10)$ \\
ACE inhibitor or ARB for LVSD & $106 / 118(90 \%)$ & $28 / 29(97 \%)$ & 0.47 & $1.07(0.98-1.18)$ \\
\hline
\end{tabular}

Abbreviations: DNR, do-not-resuscitate order; RR, relative risk; LVSD, left ventricular systolic dysfunction; ACE, angiotensin-converting enzyme; ARB, angiotensin receptor antagonist; $\mathrm{Cl}$, confidence interval.

In 23 patients, ACEi and ARB were considered but were not prescribed because of contraindications such as hypotension, renal insufficiency, or hyperkalemia. In the remaining 29 DNR and 118 non-DNR patients, 137 (93\%) were on ACEi or ARB on discharge. There was no statistically significant difference between the DNR and non-DNR groups.

\section{Prescription rate of anticoagulant for AF}

Of 394 patients, 111 (28\%) had AF, of whom 8 (7\%) died. Anticoagulant use was discussed but was not prescribed in 11 patients because of bleeding event or poor prognosis. Among the remaining 91 patients, 89 (97\%) were on anticoagulant on discharge. There was no statistically significant difference between the DNR and non-DNR groups (Table 3). 


\section{Discussion}

This study demonstrated that patients with DNR order were more likely to be elderly, have dementia, and ADLdependent. Their decision-making capacity was more likely to be incomplete. The mortality is higher in patients with DNR orders than in those without DNR orders. This study demonstrated that DNR orders did not affect quality measures of HF in our hospital, where lectures on proper implementation of DNR orders are made regularly. This study was not designed to show similarity or noninferiority of DNR order on the quality measures of inpatient HF care. Considering the $95 \% \mathrm{CI}$ of relative risk of DNR order (vs non-DNR order) on each quality measure (Table 3 ), we can infer that those were similar between the two groups. This is the first report to suggest that DNR order does not affect quality measures of inpatient HF care under circumstances shown in Figure 1.

DNR orders are intended to allow patients to forgo CPR in the event of cardiac arrest and cannot be applied to any situation other than cardiac arrest. ${ }^{6}$ The American Medical Association has published guidelines stating that a DNR order should not influence other therapeutic interventions that may be appropriate. ${ }^{6}$ Indeed, in the USA, patients with DNR orders who were admitted for AHF were less likely to undergo assessment of their left ventricular function, receive treatment with ACEi or ARB, or undergo counseling about lifestyle modifications. ${ }^{7}$ Recently, the Japanese Society of Intensive Care Medicine set the guideline for definition of DNR orders, which emphasizes that a DNR order must not be applied to procedures other than CPR and that indication for non-CPR procedures should be discussed with DNR patients as well. ${ }^{12}$ However, the interpretation of a DNR order reportedly differs and can affect the decision making for procedures other than CPR in Japan. ${ }^{10}$ Still, the DNR order carries the risk of withholding or withdrawing non-CPR procedures in Japan. Our hospital program provides internal medicine residents and physicians with lectures of DNR orders every 3 months, in which they learn the definition of DNR order and that in the presence of DNR orders, the indication for other procedures should be discussed with patients and their families in cases of advanced stage of illness. The DNR order did not affect quality measures of HF in this circumstance. The adequate method of education and frequency of DNR lectures remains to be investigated.

In addition to the AHA performance measures of inpatient $\mathrm{HF}^{3}{ }^{3}$ another quality measure of treatment for outpatients with LVSD is beta-blocker. Recent studies suggest that beta-blockers can be safely and effectively initiated in HF patients before hospital discharge and can lead to improved clinical outcomes. The Initiation Management Predischarge Process for Assessment of Carvedilol Therapy for Heart Failure trial demonstrated that predischarge initiation of carvedilol was associated with a higher rate of beta-blocker use after hospital discharge, with no increase in hospital length of stay. ${ }^{13,14}$ Initiating beta-blocker in HF patients with reduced ejection fraction before discharge is important. In our study, the DNR order did not affect beta-blocker use in LVSD patients.

In this study, $7 \%$ and $6 \%$ of patients did not receive ACEi/ARB or beta-blocker, respectively. This is problematic because in patients with reduced ejection fraction, not taking these medicines was reportedly associated with increased mortality and morbidities. ${ }^{15,16}$ Improvement of this quality measure is mandatory to improve outcome. Various registry-based performance improvement interventions, including guideline-based clinical decision support tool kits,

- $\quad$ DNR order only applies to the decision to withhold cardiopulmonary resuscitation (CPR) in the event of a cardiac arrest and should not impact other aspects of care.

- $\quad$ Patients with a DNR order should receive maximum treatment except CPR in the event of a cardiac arrest unless otherwise specified.

- Withholding or limiting treatment options in non-cardiac arrest situation such as "no intubation and comfort care only in the event of respiratory failure refractory to treatments other than mechanical ventilation" should be discussed in the context of treatment plan based on patients' preferences and values as soon as possible after admission.

Figure I Main points of the do-not-resuscitate (DNR) lectures given to participants in Tokyo Bay Urayasu Ichikawa Medical Center. 
educational materials, benchmarked quality-of-care reports, and structured educational and collaborative opportunities, provided standardized encounter forms, checklists, pocket cards, chart stickers, patient education, and other materials for the improvement of care. ${ }^{4}$ Participation in registries was associated with improvement of HF performance measures and clinical outcomes. ${ }^{17-20}$ In the Acute Decompensated Heart Failure National Registry, participating hospitals received quarterly benchmarked data reports on characteristics, treatments, quality measures, and clinical outcomes. During all 12 quarters from 2002 to 2004, quality measures improved significantly, inhospital inotrope use decreased, discharge instruction increased, and use of beta-blocker increased, which was associated with outcome improvement such as mortality and length of hospital stay. ${ }^{18}$ Hence, we need to consider incorporating these interventions to further improve quality of care.

Education on quality measures has been reported to be important for the improvement of quality of care. ${ }^{21,22} \operatorname{In} 2009$, a mandatory national accreditation program for hospitals was introduced in Denmark, with the aim of providing a framework for quality improvement for all public hospitals. ${ }^{23}$ The accreditation process improved patient care in cases of stroke, HF, ulcer, diabetes, breast cancer, and lung cancer. ${ }^{23}$ Education of quality measures as well as a nationwide accreditation system needs to be considered to improve quality of HF care in Japan.

In terms of palliative care for patients with advanced stages of illness, a holistic approach should be adopted, including end-of-life discussion, coordination of care, assessment and treatment of symptoms, and psychological, spiritual, and bereavement support. ${ }^{24}$ End-of-life discussion includes resuscitation preferences. ${ }^{8}$ ACEi and beta-blocker had been shown to improve not only mortality but also quality of life and symptoms..$^{25}$ Therefore, even if a DNR is ordered for patients with advanced-stage HF after end-oflife discussion, ACEi and beta-blocker should be continued for symptom management as long as adverse events do not occur.

The prognosis of patients hospitalized because of AHF is not good. Our study showed that inhospital mortality was $6.1 \%$, which was consistent with a previous report. ${ }^{26}$ It has been reported that DNR discussion occurred less frequently for patients with a noncancer primary diagnosis, including HF, compared with cancer patients. ${ }^{27,28}$ In cases of chronic HF, patients' health status declines slowly with occasional acute exacerbation, from which they often recover. ${ }^{29,30}$ By contrast, patients in the advanced stage of cancer have a more predict- able progressive downward trajectory with clear prognosis. ${ }^{29,31}$ Therefore, it is more challenging to estimate the prognosis of chronic $\mathrm{HF}$ than that of cancer. ${ }^{29}$ It was reported that physicians often avoided end-of-life discussion with patients with HF for fear of causing alarm and destroying hope. ${ }^{32}$ Thus, end-of-life discussion is often deferred until more emergent and less favorable occasions. Consequently, these patients often have little idea of their prognosis and may have unrealistically optimistic expectations. ${ }^{33,34}$ Although HF has a poorer prognosis than many cancers, patients with HF establish DNR orders later in the disease course and receive more life-sustaining treatments, including CPR, than cancer patients. ${ }^{35}$ As patients approach death, physicians must consider treatments to improve the quality of dying and death, focusing on palliative care, quality of life, and patient and family satisfaction rather than prolonging life. ${ }^{36,37}$ End-of-life discussion was associated with a decrease in unnecessary invasive procedures, including central venous catheter placement, intubation with mechanical ventilation, $\mathrm{CPR}$, and increase of opioid use during the advanced stage of illnesses, including HF. ${ }^{27}$ Physicians should not delay the initiation of end-of-life discussions with patients with HF to provide better quality of end of life.

In Japan, the Ministry of Health, Labor and Welfare established a guideline for the decision-making process for end-of-life care in 2007, which was updated in 2018. ${ }^{38}$ The guideline stresses the importance of not only the patient's medical condition but also their values and preferences in the decision-making process. It also defined end of life as $2-3$ months for patients with cancer and a few months to years for patients with stroke or other chronic progressive illness. ${ }^{38}$ The revised guideline in 2018 incorporated the importance of advance care planning for the first time. ${ }^{38}$ In our study, DNR was ordered among $28 \%$ of patients, whereas $66 \%$ of them did not have complete decision-making capacity, requiring discussion with surrogates. Therefore, physicians should start advance care planning in the early phase of the illness and before losing the decision-making capacity.

The present study has several limitations. First, this was a retrospective single-center study with a relatively small population. Thus, further multiple-center studies are needed to prove the role of education on DNR system in maintaining good quality measures on HF care in Japan. Second, we did not have data on quality measures before starting the DNR lectures; therefore, we cannot make a definitive conclusion that regular lectures on DNR can prevent the misuse of DNR order for HF treatment. However, in Japan, the DNR order reportedly affects non-CPR procedure, ${ }^{10}$ and we believe the lectures played an important role in its proper implementation 
for HF treatment. Third, although the adequate frequency of lectures on DNR order remains to be investigated, the frequency we use in our hospital, every 3 months, is feasible for other hospitals. Fourth, our study was not designed to show similarity or noninferiority with DNR order in comparison with the no-DNR order. However, based on a clinical point of view, the $95 \%$ CI of the relative risk of each quality measure showed similarity or noninferiority, but further larger studies are necessary to confirm this.

\section{Conclusion}

DNR orders possibly did not influence performance measures for HF in circumstances where DNR lectures are held every 3 months.

\section{Disclosure}

The authors report no conflicts of interest in this work

\section{References}

1. Benjamin EJ, Blaha MJ, Chiuve SE, et al. Heart Disease and Stroke Statistics-2017 Update: A Report From the American Heart Association. Circulation. 2017;135(10):e146-e603.

2. Konishi M, Ishida J, Springer J, et al. Heart failure epidemiology and novel treatments in Japan: facts and numbers. ESC Heart Fail. 2016;3(3):145-151.

3. Bonow RO, Bennett S, Casey DE, et al. ACC/AHA Clinical Performance Measures for Adults with Chronic Heart Failure: a report of the American College of Cardiology/American Heart Association Task Force on Performance Measures (Writing Committee to Develop Heart Failure Clinical Performance Measures): endorsed by the Heart Failure Society of America. Circulation. 2005;112(12):1853-1887.

4. Fonarow GC. Improving quality of care and outcomes for heart failure. Role of registries. Circ J. 2011;75(8):1783-1790.

5. Loertscher L, Reed DA, Bannon MP, Mueller PS. Cardiopulmonary resuscitation and do-not-resuscitate orders: a guide for clinicians. $\mathrm{Am}$ JMed. 2010;123(1):4-9.

6. Council on Ethical and Judicial Affairs, American Medical Association. Guidelines for the appropriate use of do-not-resuscitate orders. JAMA. 1991;265:1868-1871.

7. Chen JL, Sosnov J, Lessard D, Goldberg RJ. Impact of do-not-resuscitation orders on quality of care performance measures in patients hospitalized with acute heart failure. Am Heart J. 2008;156(1): 78-84.

8. Allen LA, Stevenson LW, Grady KL, et al. A scientific statement from the American Heart Association: decision making in advanced heart failure. Circulation. 2012;125:1928-1952.

9. Beach MC, Morrison RS. The effect of do-not-resuscitate orders on physician decision-making. J Am Geriatr Soc. 2002;50(12): 2057-2061.

10. Hiraoka E, Homma Y, Norisue $Y$, et al. What is the true definition of a "Do-Not-Resuscitate" order? A Japanese perspective. Int J Gen Med. 2016;9:213-220.

11. Mckee PA, Castelli WP, McNamara PM, Kannel WB. The natural history of congestive heart failure: the Framingham study. $N$ Engl J Med. 1971;285(26):1441-1446.

12. Japanese Society of Intensive Care Medicine [webpage on the Internet]. Guideline of DNR order in 2016. Available from: http://www.jsicm.org/ publication/kankoku_dnar.html. Accessed January 8, 2018.
13. Fonarow GC, Abraham WT, Albert NM, et al. Carvedilol use at discharge in patients hospitalized for heart failure is associated with improved survival: an analysis from Organized Program to Initiate Lifesaving Treatment in Hospitalized Patients with Heart Failure (OPTIMIZE-HF). Am Heart J. 2007;153(1):82.e1-e11.

14. Fonarow GC, Gheorghiade M, Abraham WT. Importance of in-hospital initiation of evidence-based medical therapies for heart failure-a review. Am J Cardiol. 2004;94(9):1155-1160.

15. Fonarow GC, Abraham WT, Albert NM, et al. Association between performance measures and clinical outcomes for patients hospitalized with heart failure. JAMA. 2007;297(1):61-70.

16. Masoudi FA, Rathore SS, Wang Y, et al. National patterns of use and effectiveness of angiotensin-converting enzyme inhibitors in older patients with heart failure and left ventricular systolic dysfunction. Circulation. 2004;110(6):724-731.

17. Fonarow GC, Abraham WT, Albert NM, et al. Influence of a performance-improvement initiative on quality of care for patients hospitalized with heart failure: results of the Organized Program to Initiate Lifesaving Treatment in Hospitalized Patients With Heart Failure (OPTIMIZE-HF). Arch Intern Med. 2007;167(14):1493-1502.

18. Fonarow GC, Heywood JT, Heidenreich PA, Lopatin M, Yancy CW; ADHERE Scientific Advisory Committee and Investigators. Temporal trends in clinical characteristics, treatments, and outcomes for heart failure hospitalizations, 2002 to 2004: findings from Acute Decompensated Heart Failure National Registry (ADHERE). Am Heart J. 2007;153(6):1021-1028.

19. Heidenreich PA, Lewis WR, Labresh KA, Schwamm LH, Fonarow GC. Hospital performance recognition with the Get With The Guidelines Program and mortality for acute myocardial infarction and heart failure. Am Heart J. 2009;158(4):546-553.

20. Fonarow GC, Albert NM, Curtis AB, et al. Improving evidence-based care for heart failure in outpatient cardiology practices: primary results of the Registry to Improve the Use of Evidence-Based Heart Failure Therapies in the Outpatient Setting (IMPROVE HF). Circulation. 2010;122(6):585-596.

21. Wong BM, Levinson W, Shojania KG. Quality improvement in medical education: current state and future directions. Med Educ. 2012;46(1):107-119.

22. Kim CS, Lukela MP, Parekh VI, et al. Teaching internal medicine residents quality improvement and patient safety: a lean thinking approach. Am J Med Qual. 2010;25(3):211-217.

23. Bogh SB, Falstie-Jensen AM, Hollnagel E, Holst R, Braithwaite J, Johnsen SP. Improvement in quality of hospital care during accreditation: a nationwide stepped-wedge study. Int $J$ Qual Health Care. 2016;28(6):715-720.

24. Morrison RS, Meier DE, Care P. Clinical practice. Palliative care. $N$ Engl J Med. 2004;350(25):2582-2590.

25. Goodlin SJ. Palliative care in congestive heart failure. J Am Coll Cardiol. 2009;54(5):386-396.

26. Lee DS, Austin PC, Rouleau JL, Liu PP, Naimark D, Tu JV. Predicting mortality among patients hospitalized for heart failure: derivation and validation of a clinical model. JAMA. 2003;290(19): 2581-2587.

27. Sasaki A, Hiraoka E, Homma Y, et al. Association of code status discussion with invasive procedures among advanced-stage cancer and noncancer patients. Int J Gen Med. 2017;10:207-214.

28. Auerbach AD, Katz R, Pantilat SZ, et al. Factors associated with discussion of care plans and code status at the time of hospital admission: results from the Multicenter Hospitalist Study. J Hosp Med. 2008;3(6):437-445.

29. Murray SA, Kendall M, Boyd K, Sheikh A. Illness trajectories and palliative care. BMJ. 2005;330(7498):1007-1011.

30. Allen LA, Stevenson LW, Grady KL, et al. Decision making in advanced heart failure: a scientific statement from the American Heart Association. Circulation. 2012;125(15):1928-1952. 
31. Lunney JR, Lynn J, Foley DJ, Lipson S, Guralnik JM. Patterns of functional decline at the end of life. JAMA. 2003;289(18):2387-2392.

32. Barclay S, Momen N, Case-Upton S, Kuhn I, Smith E. End-of-life care conversations with heart failure patients: a systematic literature review and narrative synthesis. Br J Gen Pract. 2011;61(582):e49-62.

33. Hole B, Salem J. How long do patients with chronic disease expect to live? A systematic review of the literature. BMJ Open. 2016;6(12): 012248.

34. Allen LA, Yager JE, Funk MJ, et al. Discordance between patientpredicted and model-predicted life expectancy among ambulatory patients with heart failure. JAMA. 2008;299(21):2533-2542.
35. Tanvetyanon T, Leighton JC. Life-sustaining treatments in patients who died of chronic congestive heart failure compared with metastatic cancer. Crit Care Med. 2003;31(1):60-64.

36. Patrick DL, Engelberg RA, Curtis JR. Evaluating the quality of dying and death. J Pain Symptom Manage. 2001;22(3):717-726.

37. Donaldson MS, Field MJ. Measuring quality of care at the end of life. Arch Intern Med. 1998;158(2):121-128.

38. Japanese Ministry of Health, Labor and Welfare [webpage on the Internet]. Guideline: decision making process of end of life medical care; 2018. Available from: http://www.mhlw.go.jp/stf/houdou/0000197665. html. Accessed June 12, 2018.

\section{Publish your work in this journal}

The International Journal of General Medicine is an international, peer-reviewed open-access journal that focuses on general and internal medicine, pathogenesis, epidemiology, diagnosis, monitoring and treatment protocols. The journal is characterized by the rapid reporting of reviews, original research and clinical studies across all disease areas.
The manuscript management system is completely online and includes a very quick and fair peer-review system, which is all easy to use. Visit $\mathrm{http}: / / \mathrm{www}$.dovepress.com/testimonials.php to read real quotes from published authors.

Submit your manuscript here: https://www.dovepress.com/international-journal-of-general-medicine-journal 